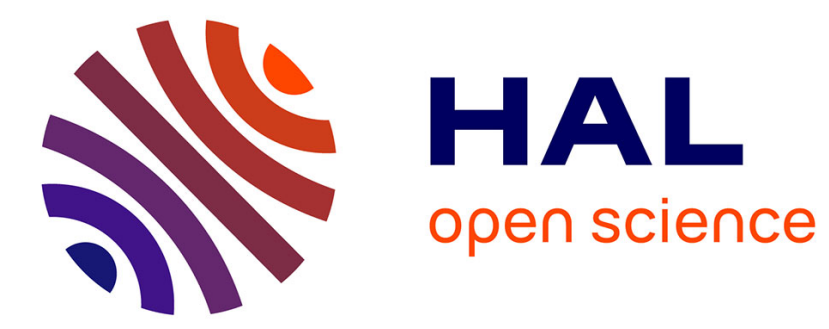

\title{
Ultrasonic propagation in a dental implant
}

Yoann Hériveaux, Bertrand Audoin, Christine Biateau, Vu-Hieu Nguyen, Guillaume Haïat

\section{To cite this version:}

Yoann Hériveaux, Bertrand Audoin, Christine Biateau, Vu-Hieu Nguyen, Guillaume Haïat. Ultrasonic propagation in a dental implant. Ultrasound in Medicine \& Biology, 2020. hal-02870870

\section{HAL Id: hal-02870870 \\ https://hal.science/hal-02870870}

Submitted on 16 Jun 2020

HAL is a multi-disciplinary open access archive for the deposit and dissemination of scientific research documents, whether they are published or not. The documents may come from teaching and research institutions in France or abroad, or from public or private research centers.
L'archive ouverte pluridisciplinaire HAL, est destinée au dépôt et à la diffusion de documents scientifiques de niveau recherche, publiés ou non, émanant des établissements d'enseignement et de recherche français ou étrangers, des laboratoires publics ou privés. 


\section{Ultrasonic propagation in a dental implant}

Yoann Hériveaux ${ }^{\text {a }}$, Bertrand Audoin ${ }^{\mathrm{b}}$, Christine Biateau ${ }^{\mathrm{b}}$, Vu-Hieu Nguyen ${ }^{\mathrm{c}}$, Guillaume Haïat $^{\mathrm{a}}$

5

${ }^{a}$ CNRS, Laboratoire Modélisation et Simulation Multi Echelle, MSME UMR 8208 CNRS, 61 avenue du Général de Gaulle, 94010 Créteil Cedex, France.

${ }^{\mathrm{b}}$ CNRS, Institut de Mécanique et d'Ingénierie, I2M UMR 5295 CNRS, 351 cours de la libération, 33405 Talence, France.

${ }^{\mathrm{c}}$ Université Paris-Est, Laboratoire Modélisation et Simulation Multi Echelle, MSME UMR 8208 CNRS, 61 avenue du Général de Gaulle, 94010 Créteil Cedex, France.

Corresponding author:

Guillaume HAÏAT

Laboratoire Modélisation Simulation Multi-Échelle, UMR CNRS 8208,

61 avenue du général de Gaulle, 94010 Créteil, France

tel : (33) 145171441

fax : (33) 145171433

e-mail : guillaume.haiat@univ-paris-est.fr 


\begin{abstract}
-
Ultrasound techniques can be used to characterize and stimulate dental implant osseointegration. However, the interaction between an ultrasonic wave and the implant-bone 5 interface (IBI) remains unclear. This study combining experimental and numerical approaches investigates the propagation of an ultrasonic wave in a dental implant by assessing the amplitude of the displacements along the implant axis.

An ultrasonic transducer was excited in transient regime at $10 \mathrm{MHz}$. Laser interferometric techniques were employed to measure the amplitude of the displacements, which varied between 3.2 to $8.9 \mathrm{~nm}$ along the implant axis. The results evidenced the propagation of a guided wave mode along the implant axis. The velocity of the first arriving signal was equal to 2110 $\mathrm{m} . \mathrm{s}^{-1}$, with frequency components lower than $1 \mathrm{MHz}$, in agreement with numerical results. Investigating guided wave propagation in dental implants should contribute to improve methods for the characterization and stimulation of the IBI.
\end{abstract}

Keywords: implant, quantitative ultrasound (QUS), finite element modeling, low intensity pulsed ultrasound (LIPUS), laser-ultrasonic 


\section{Introduction}

Dental implants are routinely used in the clinic and have allowed substantial progresses in oral and maxillofacial surgeries (Albrektsson, et al. 1988). However, a lack of implant osseointegration may lead to aseptic loosening and to surgical failures, which are difficult to anticipate (Pilliar, et al. 1986). The evolution of the implant biomechanical stability is a strong determinant of the surgical success (Haïat, et al. 2014) and may be assessed by measuring the biomechanical properties of the implant-bone interface (IBI) (Franchi, et al. 2007, Mathieu, et al. 2014).

Various approaches have been proposed to assess the stability of dental implants. X-rays or Magnetic Resonance Imaging based techniques (Gill and Shellock 2012, Shalabi, et al. 2007) are not adapted due to the distortion effects related to the presence of titanium. Impact methods such as for example the Periotest (Medizintechnik Gulden, Bensheim, Germany) (Schulte, et al. 1983, Van Scotter and Wilson 1991) have also been developed, but present reproducibility issues due to their sensitivity to striking height and handpiece angulation (Meredith, et al. 1998).

Resonance frequency analysis (RFA) (Meredith et al., 1996; Georgiou and Cunningham, 2001; Pastrav et al., 2009) is the most commonly used biomechanical technique to investigate the stability of dental implants. However, RFA cannot be used to directly identify the IBI characteristics (Aparicio, et al. 2006), and the orientation and fixation of the transducers were found to have important effects on the Implant Stability (Pattijn, et al. 2007, Vayron, et al. 2018, Vayron, et al. 2018).

The use of quantitative ultrasound (QUS) constitutes an attractive alternative to assess dental implant stability, as suggested in (de Almeida, et al. 2007). During healing, the boneimplant contact (BIC) ratio, the elastic properties and the mass density of periprosthetic bone tissue increase (Mathieu, et al. 2011, Vayron, et al. 2012, Vayron, et al. 2014) as a function of 
time, which lead to a decrease of the gap of acoustical properties at the IBI. As a result, the reflection coefficient at the IBI decreases as function of healing time, which was evidenced in a controlled and standardized situation (Mathieu, et al. 2012). Based on these preliminary results, a $10 \mathrm{MHz}$ QUS device consisting of an ultrasound transducer placed at the emerging end of the implant was first validated using cylindrical implants (Mathieu, et al. 2011), then in vitro using dental implants (Vayron, et al. 2013, Vayron, et al. 2014), and eventually in vivo (Vayron, et al. 2014). More recent studies showed that this QUS method was significantly more sensitive to changes of periprosthetic bone tissue compared to the RFA in vitro (Vayron, et al. 2018) and in vivo (Vayron, et al. 2018).

Ultrasound and more specifically low intensity pulsed ultrasound (LIPUS) may also be employed to stimulate bone remodeling (Duarte 1983, Heckman, et al. 1994). Different studies have shown the potential of ultrasound to stimulate osseointegration using animal models with bioglass implants (Lin, et al. 1995), porous cylinders (Tanzer, et al. 1996, Tanzer, et al. 2001) and dental implants (Hsu, et al. 2011, Liu, et al. 2012, Nakanishi, et al. 2011). More recently, an ultrasonic therapy was assessed clinically and confirmed that LIPUS can be used to promote dental implants osseointegration (Akram Abdulhameed, et al. 2017). However, the precise mechanism of action of LIPUS remains poorly understood (Claes and Willie 2007, Dimitriou and Babis 2007, Padilla, et al. 2014) and strongly depends on the nature of the signal corresponding to the stimulation.

The amount of energy transmitted to the IBI is an important parameter for applications corresponding to the ultrasonic characterization and stimulation of the IBI. Concerning the characterization, the acoustical energy should be sufficiently low so that the tissues around the implant would not be damaged due to excessive micromotion which could be detrimental to osseointegration (Szmukler-Moncler, et al. 1998). Concerning the stimulation, the acoustical energy must be sufficiently high to obtain a significant impact on the implant osseointegration. 
Note that vibrations generated by a LIPUS device to stimulate bone repair after a fracture have already been quantified using laser interferometric methods (Harrison, et al. 2016). However, to the best of our knowledge, no study in the literature focused on the estimation of the displacement induced by an ultrasonic wave at the implant surface.

The interaction between an ultrasonic wave and a dental implant still remains unclear due to the complex geometrical configuration. Understanding the phenomena occurring when an ultrasound wave propagates in a dental implant would be useful for both stimulation and characterization purposes. To do so, numerical simulation of wave propagation in a cylinder mimicking dental implant (Mathieu, et al. 2011, Vayron, et al. 2015) as well as in a dental implant (Vayron, et al. 2016) has already been carried out, using finite difference and finite element modeling, and validated experimentally. The guided nature of the ultrasonic wave propagating in cylindrical implants has been evidenced in (Mathieu, et al. 2011, Vayron, et al. 2015) but no previous study was able to show whether guided waves could propagate in dental implants.

The aim of the present study is to investigate the interaction between an ultrasonic wave and a dental implant using experimental and numerical approaches. We aim at measuring the amplitude of the displacements generated by an ultrasonic transducer screwed into the dental implant. To do so, laser interferometric techniques were employed and the data were processed to derive the velocity and the frequency of the first wave propagating along the implant axis. The experimental results were compared to their numerical counterparts. 


\section{Material and methods}

\section{Dental implant}

A $10 \mathrm{~mm}$ long and $4.1 \mathrm{~mm}$ diameter conical dental implant made of grade 5, Ti-Al6-V4 titanium alloy, was used in the present study. The implant was manufactured by Zimmer Biomet

5 (Warsaw, Indiana, USA) under the reference TSVT4B10. The geometrical configuration of the measurements is shown in Fig. 1. The implant was slightly polished locally on its extremity and laterally in regions of interest where laser ultrasonic measurements were carried out. Polishing was necessary to obtain a planar surface and therefore maximize specular reflection of the laser interferometer at the implant surface. Sensitivity to the surface displacement and signal to noise ratio were thereby optimized.

\section{Ultrasonic device}

The ultrasonic device composed of a $5 \mathrm{~mm}$ diameter planar ultrasonic monoelement contact transducer was designed by our group and manufactured by Imasonic (Voray-surl'Ognon, France). It generates a broadband ultrasonic pulse propagating perpendicularly to its active surface. The probe was used in echographic mode. Its center frequency was equal to 10 $\mathrm{MHz}$, with a frequency bandwidth approximately equal to 6-14 MHz. The probe was rigidly attached to a titanium alloy dental healing abutment with a $5 \mathrm{~mm}$ long threaded part, which can be screwed into the implant, similarly as what was done in (Vayron, et al. 2018, Vayron, et al. 2018). The healing abutment was screwed into the implant with a torque of $3.5 \mathrm{~N} . \mathrm{cm}$, which is around 10 times lower than values recommended for implant insertion (Kanawati, et al. 2009), thus guaranteeing that the measurement is noninvasive. The ultrasonic probe was connected to a pulse generator (Sofranel, model 5052PR) via a standard coaxial cable. The pulse excitation had an amplitude of $100 \mathrm{~V}$ and a duration of $200 \mathrm{~ns}$. 


\section{Laser-ultrasonic measurement}

A laser interferometer (BMI SH 140, B.M.Industries, 91029 Evry, France), suited for the detection of ultrasound at the surface of cylinders with millimeter diameter (Clorennec and

5 Royer 2004, Pan, et al. 2006), was used in order to evaluate the amplitude of the displacements occurring at the implant surface. The displacements were measured at the extremity of the implant and at different positions along the implant axis. The surface of the implant where the displacements were measured was set perpendicularly to the axis of the beam of the laser interferometer so that the laser signal reflected by the implant could be correctly received by the laser interferometer. The size of the laser beam at the implant surface was about $100 \mu \mathrm{m}$. The measurements could not be made at regular spacing intervals because of the imperfect surface conditions of the implant, which did not allow to carry out the measurements for all locations of the implant surface. Therefore, we tried to space measurements by around $0.5 \mathrm{~mm}$ from each other, but precise positions of measures were adapted so that the laser interferometer correctly received signals reflected by the implant. Only one channel was used for each measurement, which were made successively at each position. An oscilloscope was used to capture the signal given by the interferometer. Signals were averaged 500 times for each measurement. A calibration procedure allowed to derive the amplitude of the displacements at the surface of the implant and the frequency of the displacements was estimated from these signals. The reproducibility of the measurements was assessed by disassembling the entire set up and reproducing the measurements.

Similarly as in (Bossy, et al. 2002), for all measured signals, the time of flight of the first arriving signal (FAS) was defined as the time for which signals first had an amplitude superior to a threshold equal to $0.5 \mathrm{~nm}$, which is around 2.5 times higher to the magnitude of the noise. 
The slope $b$ of the linear interpolation of the variation of the time of flight of the FAS as a function of the position along the implant axis (Sasso, et al. 2009) allowed to derive the velocity of the FAS $v_{F A S}$ following:

$$
v_{F A S}=\frac{1}{b}
$$

\section{Numerical modeling and simulation}

The experimental configuration was reproduced numerically using a $2 \mathrm{D}$ axisymmetric model, corresponding to half of the schematic representation shown in Fig. 1a. The approach was detailed in (Vayron, et al. 2015, Vayron, et al. 2016) and is briefly reminded in what follows. All the boundaries of the implant and of the ultrasonic transducer were considered as free. All parts considered in this model were assumed to have homogeneous isotropic mechanical properties and to be composed of Ti-Al6-V4. The mechanical properties of the titanium alloy considered in this study are the following: the longitudinal wave velocity was $C_{p}$ $=5790 \mathrm{~m} \cdot \mathrm{s}^{-1}$, the shear wave velocity was $C_{s}=3100 \mathrm{~m} \cdot \mathrm{s}^{-1}$ and the mass density was $\rho=4420$ $\mathrm{kg} \cdot \mathrm{m}^{-3}$. All numerical values were taken from (Pattijn, et al. 2007, Pattijn, et al. 2006).

The dynamic equations of wave propagation were solved in the implant and reads:

$$
\rho \ddot{\boldsymbol{u}}-\operatorname{div} \boldsymbol{\sigma}=\mathbf{0}
$$

where $\boldsymbol{u}$ is the displacement vector and $\boldsymbol{\sigma}$ is the stress tensor.

The ultrasonic attenuation in Ti-Al6-V4 highly depends on the frequency and on the microstructure of titanium alloy. Typical values of bulk viscosity $\eta$ were found between 1 and 15 Pa.s in the literature (Carreon, et al. 2017, Li, et al. 2001, Panetta and Thompson 1999). In this study, the same viscosity $\eta$, which is equal to 5 Pa.s, was used for both bulk and shear waves. The components of the stress tensor $\sigma_{i j}$ in Ti-Al6-V4 are related to the components of the strain tensor $\varepsilon_{i j}$ by the equation: 


$$
\sigma_{i j}=2 \mu \varepsilon_{i j}+\lambda \delta_{i j} \varepsilon_{k k}+\eta \delta_{i j} \dot{\varepsilon}_{k k}+2 \eta \dot{\varepsilon}_{i j}
$$

where $\delta_{i j}$ is the Kronecker delta, and $\lambda=63.5 \mathrm{GPa}$ and $\mu=42.3 \mathrm{GPa}$ are the Lamé coefficients corresponding to the mechanical properties of the titanium alloy $\left(C_{p}, C_{s}, \rho\right)$ given above.

The acoustical source is modeled by a broadband ultrasonic pulse with a normal stress $\sigma_{11}(t)$ applied at the top surface of the transducer defined by:

$$
\sigma_{11}(t)=A e^{-4\left(f_{\mathrm{c}} t-1\right)^{2}} \sin \left(2 \pi f_{\mathrm{c}} t\right)
$$

where $A$ is an arbitrary constant (all computations are linear) representing the signal amplitude and $f_{c}$ is its central frequency. Several values of $f_{c}$ were considered throughout this study (1 MHz, $5 \mathrm{MHz}$ and $10 \mathrm{MHz}$ ).

The discretization of the equations described above leads to a transient linear dynamic problem, which was solved using a finite element software (COMSOL Multiphysics, Stockholm, Sweden). The implicit direct time integration generalized- $\alpha$ scheme (Chung and Hulbert 1993) was used to calculate the transient response of the system. The implant was meshed by structured quadrangular quadratic elements with a maximal size of $10 \mu \mathrm{m}$. The time step was chosen equal to $5 \mathrm{~ns}$, and simulations were run during $50 \mu \mathrm{s}$.

Once the solution was obtained, the displacements were determined on the extremity of the implant. To do so, the signal representing the displacement perpendicular to the implant surface was averaged along a vertical line of $150 \mu \mathrm{m}$ located the closest as possible to the external surface of the implant. 


\section{Results}

\section{Reproducibility of the measurements}

Figure 2 represents the signals measured at the extremity of the implant for 3 different measurements after the ultrasonic set-up had been screwed and unscrewed from within the implant. The aspect of the signals and the frequency contents are globally identical for all measurements. However, a slight change of up to $25 \%$ in the maximum amplitude of the displacements was observed, which was presumably due to slight changes in the positioning and in the tightening of the implant. Nevertheless, Fig. 2 shows the relatively good reproducibility of the measurements in terms of signal pattern.

\section{Experimental measurements of displacements along the implant threading}

The magnitude of the noise of the radiofrequency signals was estimated by considering the maximum amplitude of displacements before the time of flight of the FAS (e.g. for time values between 0 and $3 \mu \mathrm{s}$ in Fig. 2). It was about $0.2 \mathrm{~nm}$ for each reproduction of the measurement, which is 15 to 60 times lower than the amplitude of the measured signal. Figure 3 shows the variation of the measured displacement as a function of time at three different locations along the implant threading. Figure 3 shows that for each position, and especially towards the end of the threading (Fig. 3c), the most energetic contribution is of relatively low frequency and arrives at a relatively short time, as was also observed at the extremity of the implant (see Fig. 2). This low frequency contribution corresponds to the main component of the ultrasonic wave, whereas the contributions issued from multiple reflections of the ultrasonic wave on the implant boundaries are less energetic and arrive later.

Figure 4 represents the frequency spectra associated to the three signals shown in Fig. 3. Most components of the spectra are comprised between 0 and 1.5 MHz. For each spectrum, energetic contributions are present around $300 \mathrm{kHz}$ and $900 \mathrm{kHz}$. For relative low values of $x$ 
(Fig. 4a and 4b), an important number of contributions may be distinguished around $300 \mathrm{kHz}$ and $900 \mathrm{kHz}$, while for higher values of $x$ (Fig. 4c), the signal has fewer frequency components.

Figure 5a shows the variation of the peak-to-peak amplitude of the displacement as a function of time along the implant axis (corresponding to the $x$ direction), which is comprised between $3.2 \mathrm{~nm}$ and $8.9 \mathrm{~nm}$. At the extremity of the implant, the maximum value of the amplitude of displacements was equal to $9.7 \mathrm{~nm}$. Considering a frequency of $300 \mathrm{kHz}$, which is the main component of the frequency spectra for this position (see Fig. 6b), the aforementioned displacement amplitude corresponds to a particle velocity of around $v_{m}=18$ mm. $\mathrm{s}^{-1}$. As shown in Fig. 5a, the maximum amplitude of the displacement globally decreases during the first $3.5 \mathrm{~mm}$, but then alternates between increasing and decreasing to reach two local maxima around $\mathrm{x}=4.5 \mathrm{~mm}$ and around $\mathrm{x}=7.5 \mathrm{~mm}$. No repositioning or unscrewing of the implant was realized through the measurements presented on Fig. 5a. Therefore, the reproducibility was significantly better than the one obtained in Fig. 2, with a variation of the displacement amplitude inferior to $10 \%$ when reproducing measures for the same position.

Figure $5 \mathrm{~b}$ shows the variation of the time of flight of the FAS as a function of the position of the measurement along the x-axis. A linear regression analysis was performed and indicates a wave propagation velocity of around $2110 \mathrm{~m} \cdot \mathrm{s}^{-1}$, which corresponds to the FAS velocity (Haïat, et al. 2009).

\section{Numerical validation}

Figure 6 shows the comparison between numerical and experimental results obtained at the implant extremity. The amplitude of the numerical signals was normalized so that it corresponds to the experimental measurements. Figure $6 \mathrm{~b}$ indicates that the frequency components of the experimental and numerical data are lower than the central frequency of the 
excitation signal $\left(f_{c}=10 \mathrm{MHz}\right)$. However, frequency components obtained numerically are higher than for experimental data, and are mostly comprised between 0 and $4 \mathrm{MHz}$.

Figure 7 shows the frequency spectra of numerical signals obtained at the extremity of the implant for transducers with different central frequencies $f_{c}$ equal to $1 \mathrm{MHz}, 5 \mathrm{MHz}$ and 10 MHz. Spectra obtained with $5 \mathrm{MHz}$ and $10 \mathrm{MHz}$ transducers are nearly identical, with the main components comprised between $100 \mathrm{kHz}$ and $1.7 \mathrm{MHz}$, but also a few other components between $1.7 \mathrm{MHz}$ and $3.5 \mathrm{MHz}$. The spectrum obtained for a $1 \mathrm{MHz}$ transducer is slightly different since it does not contain any frequency component over 1.5 MHz. The results show that the spectrum of the signal weakly depends on the excitation frequency when considering frequencies over $5 \mathrm{MHz}$.

\section{Discussion}

The originality of the present study is to propose the combination of experimental and of numerical approaches in order to provide further insight on the propagation of an ultrasonic wave in a dental implant. Such investigation is particularly important in the context of ultrasound characterization and stimulation of dental implant osseointegration.

\section{Propagation of a guided wave in a dental implant}

Figure 4 shows that the frequency spectra corresponding to the displacement measured experimentally are mainly composed of low frequencies (mostly between $300 \mathrm{kHz}$ and $2 \mathrm{MHz}$ ) compared to the excitation central frequency (10 MHz). Figure 4 also shows that the amplitude of high frequency components tends to decrease along the implant axis. The observation of lowfrequency components may result from the attenuation of the ultrasonic wave while propagating along the $1 \mathrm{~cm}$ long titanium implant. 
Although the frequency range obtained numerically is slightly higher than that obtained experimentally, the numerical results shown in Fig. $6 \mathrm{~b}$ confirm that only low frequencies (between 1 and $3 \mathrm{MHz}$ ) are obtained in the implant. The higher frequencies obtained numerically may be explained through different modeling approximations. First, the ultrasonic excitation defined by Eq. (4) might not have the exact same characteristics (center frequency, spectral band) as in experiments. Second, the transducer was considered as a perfect planar piston source. Third, the contact between the transducer and the implant was considered as perfect in the simulations. Fourth, the surface roughness of the implant was not considered, although it has been shown to influence the ultrasonic response of the IBI (Hériveaux, et al. in press, Heriveaux, et al. 2019, Heriveaux, et al. 2018).

Moreover, Fig. $5 b$ indicates that the wave velocity of the FAS is equal to $2110 \mathrm{~m} . \mathrm{s}^{-1}$, which is significantly lower than the bulk longitudinal velocity $\left(C_{p}=5810 \mathrm{~m} \cdot \mathrm{s}^{-1}\right.$ in titanium alloys). These two results (slow and low frequency wave propagation) indicate the presence of a dispersive ultrasound wave guided by the implant structure.

In order to understand the value of the wave velocity obtained for the FAS, the dispersion curves of phase velocities were numerically assessed using the numerical model, similarly to what was done in (Barshinger and Rose 2004, Djili and Fouad 2010). Radial displacements were punctually assessed every $10 \mu \mathrm{m}$ along the dotted line shown in Fig. 1a. A double Fourier transform with respect to time and space was then performed to obtain the dispersion curves shown in Fig. 8. The maximum amplitudes of the double Fourier transform were obtained for frequencies between 0.7 to $1.3 \mathrm{MHz}$ and phase velocities between 1900 and $2400 \mathrm{~m} . \mathrm{s}^{-1}$, which corresponds to frequencies observed experimentally (see Fig. 4) and to the experimental FAS velocity (equal to $2110 \mathrm{~m} \cdot \mathrm{s}^{-1}$ ). 
Numerical dispersion curves were also compared to analytical ones obtained using the software Disperse (Pavlakovic, et al. 1997) in order to better understand the different modes of propagation of the ultrasonic wave. To do so, the dental implant was approximated by a hollow cylinder made of titanium alloy to obtain a simple model that could be solved analytically by considering the dispersion equation associated to the Disperse software. The values of the internal and external diameters of the cylinder $(1.6$ and $3.6 \mathrm{~mm})$ were determined based on the implant geometry (see Fig. 1). The white lines in Fig. 8 represent the analytical dispersion curves corresponding to the first three longitudinal modes propagating in the hollow cylinder. Some similarities concerning the longitudinal modes $\mathrm{L}(0,1)$ and $\mathrm{L}(0,2)$ may be observed for the dispersion curves obtained with the analytical and numerical models. For frequencies higher than $4 \mathrm{MHz}$, the phase velocity reaches a constant value around $2900 \mathrm{~m} \cdot \mathrm{s}^{-1}$ in both cases. However, under $4 \mathrm{MHz}$, many low frequency components were obtained numerically and could not be related to any of the modes determined analytically. The differences between the analytical and numerical models may be due to (i) the approximate geometry considered for the analytical model and (ii) the multiple scattering of the ultrasonic wave occurring numerically due to the complex geometry considered (see Fig. 1a). Nevertheless, for a frequency of 700 $\mathrm{kHz}$, the high velocity components (over $6000 \mathrm{~m} \cdot \mathrm{s}^{-1}$ ) found numerically correspond to the vertical asymptote obtained analytically at the same frequency for the mode $L(0,2)$. Finally, the third longitudinal mode $\mathrm{L}(0,3)$ and higher longitudinal modes were not observed numerically since they occur for higher frequencies (over $2.5 \mathrm{MHz}$ ) than $\mathrm{L}(0,1)$ and $\mathrm{L}(0,2)$.

\section{Influence of the frequency of the excitation signal}

The results shown in Fig. 7 indicate that the frequency components of the ultrasonic response of the implant weakly depend on the central frequency of the excitation signal, as it is 
expected for a guided wave. This result may affect the choice of the central frequency of the transducer which may be changed between 3 and $10 \mathrm{MHz}$ without affecting significantly wave propagation in the dental implant, as shown in Fig. 7. Note that previous studies on the characterization of dental implant stability used a center frequency of $10 \mathrm{MHz}$ (Vayron, et al. 2018, Vayron, et al. 2018, Vayron, et al. 2014). Reducing the frequency down to $3 \mathrm{MHz}$ would therefore not significantly modify the ultrasonic propagation and the results obtained with the ultrasonic set-up. However, further experimental studies are needed to confirm this point.

\section{Amplitude of displacement and transmitted energy}

The experimental results show that the amplitude of the displacement reaches local maximum values around $x=4.7 \mathrm{~mm}$ and around $x=7.3 \mathrm{~mm}$ (see Fig. 5a). These locations correspond to regions of interest where the implant geometry has an internal cavity, at the end of the abutment of the transducer and at the extremity of the implant (see Fig. 1). These results may be explained by a concentration of the acoustic energy in regions where the section is lower compared to regions where the cylinder is full. However, the amplitude of the displacement always remain inferior to $10 \mathrm{~nm}$, which is far from the critical level of micromotion (around 50 $\mu \mathrm{m}$ to $150 \mu \mathrm{m})$ that may prevent osseointegration (Szmukler-Moncler, et al. 1998).

Regulations from the US Food and Drug Administration (FDA) indicate an exposure limit of $720 \mathrm{~mW} / \mathrm{cm}^{2}$ for diagnostic ultrasound equipment (2017). In our case, the average Karczub 2003):

$$
I=\frac{1}{2} Z_{T i} v_{m}^{2}
$$


where $Z_{T i}$ is the acoustical impedance of the titanium alloy and $v_{m}$ is the particle velocity. Considering the particle velocity measured at the extremity of the implant (around $18 \mathrm{~mm} \cdot \mathrm{s}^{-1}$, see the Results section), the average intensity sent by the ultrasonic transducer is around 460 $\mathrm{mW} / \mathrm{cm}^{2}$, which therefore respects FDA requirements.

The excitation signal sent to the transducer is similar to the one used in previous studies by our group on the QUS device aiming at assessing implant stability (Mathieu, et al. 2011, Vayron, et al. 2013, Vayron, et al. 2014, Vayron, et al. 2014). Most studies on LIPUS stimulation of implant osseointegration focused on lower intensities, around 30 or $40 \mathrm{~mW} / \mathrm{cm}^{2}$ (Akram Abdulhameed, et al. 2017, Hsu, et al. 2011, Liu, et al. 2012, Tanzer, et al. 1996, Ustun, et al. 2008), but applied during longer duration in the harmonic regime, while we worked in transient mode. Therefore, the amplitude of the displacement measured herein are not representative of displacements generated by LIPUS stimulation. The present study emphasizes that mechanical stimulation induced by ultrasound is highly sensitive to the geometrical configuration and provides an estimation of the energy sent by an ultrasonic wave to the IBI.

As described above, the geometrical configuration strongly influences the distribution of the acoustical energy at the IBI, which in turn significantly influences bone regeneration at the wound site (Massari, et al. 2019). For example, (Harrison, et al. 2016) investigated nanomotion induced by LIPUS on a fracture site and measured displacements between 0.16 and $0.56 \mathrm{~nm}$ with a laser interferometer. It concluded that this precise range of motions promoted an intra-cellular pathway stimulating bone growth. At the same time, a review of controlled trials indicated that the efficiency of LIPUS on bone regeneration could not be proved (Schandelmaier, et al. 2017). A possible hypothesis is that LIPUS stimulation failures might be explained by ill-adapted choices of LIPUS parameters for the considered configuration, resulting in mechanical effects that may have no impact on bone regeneration. 


\section{Limitations}

This study has several limitations. First, the implant measured experimentally had been partially polished on one side, which removed a small part of its threading and may have influenced the results. However, the surface where the implant was polished was around $15 \%$ of the implant surface and the geometry was not significantly modified.

Second, the present study only considered the situation where the implant was surrounded by air. The values of displacement of the implant are likely to be lower when considering an implant surrounded by bone or by soft tissues, and the energy transmitted to these media would therefore be lower. Considering implants inserted in bone tissue would be of interest to precisely quantify the intensity transmitted by an ultrasonic wave to the IBI. However, the present study provides upper bound of the acoustic energy applied at the implant surface.

Third, several approximations have been made in the numerical model. In particular, the acoustical source was considered to have a uniform pressure. The geometry of the implant was also approximated, since real threading cannot be thoroughly axisymmetric. A 3D model would therefore depict more precisely the real configuration. Moreover, different values of attenuation coefficient were found in the literature for the titanium alloy, and the one that was chosen in this study may therefore be approximate. Eventually, other types of implant geometry should also be considered and may affect the results.

\section{Conclusion}

This study emphasizes that the propagation of an ultrasonic wave in a titanium dental implant is guided by the implant structure. For characterization purposes, the results indicate 
that it is not necessary to consider high frequency transducers since ultrasound propagate at frequencies comprised between $300 \mathrm{kHz}$ and $2 \mathrm{MHz}$ in the implant. For stimulation purposes, the results indicate that the intensity transmitted to the IBI is highly sensitive to the considered structure.

\section{Acknowledgements}

This project has received funding from the European Research Council (ERC) under the European Union's Horizon 2020 research and innovation program (grant agreement No 682001, project ERC Consolidator Grant 2015 BoneImplant). 


\section{References}

Akram Abdulhameed E, Enezei H, Omar M, Komori A, Sugita Y, Hegazy F, Samsudin A, Maeda H, Alam $M$. The Effect of Low Intensity Pulsed Ultrasound Therapy on Osseointegration and Marginal Bone Loss Around Dental Implants. Journal of Hard Tissue Biology 2017; 26:323-30.

Albrektsson T, Dahl E, Enbom L, Engevall S, Engquist B, Eriksson AR, Feldmann G, Freiberg N, Glantz P$\mathrm{O}$, Kjellman $\mathrm{O}$, Kristersson L, Kvint S, Köndell P-Å, Palmquist J, Werndahl L, Åstrand P. Osseointegrated Oral Implants. Journal of Periodontology 1988; 59:287-96.

Aparicio C, Lang NP, Rangert B. Validity and clinical significance of biomechanical testing of implant/bone interface. Clin Oral Implants Res 2006; 17 Suppl 2:2-7.

Barshinger JN, Rose JL. Guided wave propagation in an elastic hollow cylinder coated with a viscoelastic material. IEEE Transactions on Ultrasonics, Ferroelectrics, and Frequency Control 2004; 51:1547-56

Bossy E, Talmant M, Laugier P. Effect of bone cortical thickness on velocity measurements using ultrasonic axial transmission: A 2D simulation study. The Journal of the Acoustical Society of America 2002; 112:297-307.

Carreon $\mathrm{H}$, Carreon M, Dueñas A. Assessment of precipitates of aged Ti-6Al-4V alloy by ultrasonic attenuation. Philosophical Magazine 2017; 97:58-68.

Chung J, Hulbert GM. A Time Integration Algorithm for Structural Dynamics With Improved Numerical Dissipation: The Generalized- $\alpha$ Method. Journal of Applied Mechanics 1993; 60:371-75.

Claes L, Willie B. The enhancement of bone regeneration by ultrasound. Prog Biophys Mol Biol 2007; 93:384-98.

Clorennec D, Royer D. Investigation of surface acoustic wave propagation on a sphere using laser ultrasonics. Applied Physics Letters 2004; 85:2435-37.

de Almeida MS, Maciel CD, Pereira JC. Proposal for an Ultrasonic Tool to Monitor the Osseointegration of Dental Implants. 2007; 7:1224-37.

Dimitriou R, Babis G. Biomaterial osseointegration enhancement with biophysical stimulation. J Musculoskelet Neuronal Interact 2007; 7:257-63.

Djili S, Fouad B. Propagation of guided waves in a hollow circular cylinder application to non destructive testing. The European Physical Journal Conferences 2010; 6 .

Duarte LR. The stimulation of bone growth by ultrasound. Archives of orthopaedic and traumatic surgery 1983; 101:153-59.

FDA. 2017 Marketing Clearance of Diagnostic Ultrasound Systems and Transducers: US Department of Health and Human Services, Food and Drug Administration, Center for Devices and Radiological Health.

Franchi M, Bacchelli B, Giavaresi G, De Pasquale V, Martini D, Fini M, Giardino R, Ruggeri A. Influence of Different Implant Surfaces on Peri-Implant Osteogenesis: Histomorphometric Analysis in Sheep. Journal of Periodontology 2007; 78:879-88.

Gill A, Shellock FG. Assessment of MRI issues at 3-Tesla for metallic surgical implants: findings applied to 61 additional skin closure staples and vessel ligation clips. J Cardiovasc Magn Reson 2012; 14:3.

Haïat G, Naili S, Grimal Q, Talmant M, Desceliers C, Soize C. Influence of a gradient of material properties on ultrasonic wave propagation in cortical bone: Application to axial transmission. The Journal of the Acoustical Society of America 2009; 125:4043-52.

Haïat G, Wang H-L, Brunski J. Effects of Biomechanical Properties of the Bone-Implant Interface on Dental Implant Stability: From In Silico Approaches to the Patient's Mouth. Annual Review of Biomedical Engineering 2014; 16:187-213.

Harrison A, Lin S, Pounder N, Mikuni-Takagaki Y. Mode \& mechanism of low intensity pulsed ultrasound (LIPUS) in fracture repair. Ultrasonics 2016; 70:45-52.

Heckman J, Ryaby J, McCabe J, Frey J, Kilcoyne R. Acceleration of Tibial Fracture-Healing by NonInvasive, Low-Intensity Pulsed Ultrasound. J Bone Joint Surg Am. 1994; 76:26-34. 
Hériveaux $\mathrm{Y}$, Haiat $\mathrm{G}$, Nguyen $\mathrm{VH}$. Reflection of an ultrasonic wave on the bone-implant interface: comparison of 2D and 3D numerical models. JASA-EL in press.

Heriveaux Y, Nguyen VH, Brailovski V, Gorny C, Haiat G. Reflection of an ultrasonic wave on the boneimplant interface: Effect of the roughness parameters. J Acoust Soc Am 2019; 145:3370.

Heriveaux Y, Nguyen VH, Haiat G. Reflection of an ultrasonic wave on the bone-implant interface: A numerical study of the effect of the multiscale roughness. J Acoust Soc Am 2018; 144:488.

Hsu S-K, Huang W-T, Liu B-S, Li S-M, Chen H-T, Chang C-J. Effects of near-field ultrasound stimulation on new bone formation and osseointegration of dental titanium implants in vitro and in vivo. Ultrasound in Med. \& Bio. 2011; 37:403-16.

Kanawati A, Richards MW, Becker JJ, Monaco NE. Measurement of Clinicians' Ability to Hand Torque Dental Implant Components. Journal of Oral Implantology 2009; 35:185-88.

Li A, Roberts R, Margetan FJ, Thompson RB. Study of the effect of microstructure on ultrasonic signal attenuation. AIP Conference Proceedings 2001; 557:1322-29.

Lin F, Lin C, Lu C, Liu H, Wang C. The effects of ultrasonic stimulation on DP-bioglass bone substitute. Med Eng Phys 1995; 17:20-26.

Liu Q, Liu X, Liu B, Hu K, Zhou X, Ding Y. The effect of low-intensity pulsed ultrasound on the osseointegration of titanium dental implants. Br J Oral Maxillofac Surg 2012; 50:244-50.

Massari L, Benazzo F, Falez F, Perugia D, Pietrogrande L, Setti S, Osti R, Vaienti E, Ruosi C, Cadossi R. Biophysical stimulation of bone and cartilage: state of the art and future perspectives. International Orthopaedics 2019; 43:539-51.

Mathieu V, Anagnostou F, Soffer E, Haiat G. Numerical simulation of ultrasonic wave propagation for the evaluation of dental implant biomechanical stability. J. Acoust. Soc. Am. 2011; 129:406272.

Mathieu V, Anagnostou F, Soffer E, Haïat G. Ultrasonic Evaluation of Dental Implant Biomechanical Stability: An In Vitro Study. Ultrasound in Medicine \& Biology 2011; 37:262-70.

Mathieu V, Fukui K, Matsukawa M, Kawabe M, Vayron R, Soffer E, Anagnostou F, Haiat G. MicroBrillouin scattering measurements in mature and newly formed bone tissue surrounding an implant. J Biomech Eng 2011; 133:021006.

Mathieu V, Vayron R, Richard G, Lambert G, Naili S, Meningaud JP, Haiat G. Biomechanical determinants of the stability of dental implants: influence of the bone-implant interface properties. J Biomech 2014; 47:3-13.

Mathieu V, Vayron R, Soffer E, Anagnostou F, Haiat G. Influence of healing time on the ultrasonic response of the bone-implant interface. Ultrasound Med Biol 2012; 38:611-8.

Meredith N, Friberg B, Sennerby L, Aparicio C. Relationship between contact time measurements and PTV values when using the Periotest to measure implant stability. Int J Prosthodont 1998; 11:269-75.

Nakanishi Y, Wang P-L, Ochi M, Nakanishi K, Matsubara H. Low-intensity Pulsed Ultrasound Stimulation Significantly Enhances the Promotion of Bone Formation Around Dental Implants. Journal of Hard Tissue Biology 2011; 20:139-46.

Norton MP, Karczub DG. Fundamentals of Noise and Vibration Analysis for Engineers. Cambridge: Cambridge University Press, 2003.

Padilla F, Puts R, Vico L, Raum K. Stimulation of bone repair with ultrasound: A review of the possible mechanic effects. Ultrasonics 2014; 54:1125-45.

Pan Y, Li L, Rossignol C, Audoin B, Chigarev N. Acoustic waves generated by a laser line pulse in a hollow cylinder. Ultrasonics 2006; 44 Suppl 1:e843-7.

Panetta PD, Thompson RB. Ultrasonic Attenuation in Duplex Titanium Alloys, In: Thompson DO and Chimenti DE, eds. Review of Progress in Quantitative Nondestructive Evaluation: Volume 18A18B. Boston, MA: Springer US, 1999. 1717-24.

Pattijn V, Jaecques SVN, De Smet E, Muraru L, Van Lierde C, Van der Perre G, Naert I, Vander Sloten J. Resonance frequency analysis of implants in the guinea pig model: Influence of boundary conditions and orientation of the transducer. Medical Engineering \& Physics 2007; 29:182-90. 
Pattijn V, Van Lierde C, Van der Perre G, Naert I, Vander Sloten J. The resonance frequencies and mode shapes of dental implants: Rigid body behaviour versus bending behaviour. A numerical approach. Journal of Biomechanics 2006; 39:939-47.

Pavlakovic B, Lowe M, Alleyne D, Cawley P. Disperse: A General Purpose Program for Creating Dispersion Curves, In: Thompson DO and Chimenti DE, eds. Review of Progress in Quantitative Nondestructive Evaluation: Volume 16A. Boston, MA: Springer US, 1997. 185-92.

Pilliar RM, Lee JM, Maniatopoulos C. Observations on the effect of movement on bone ing rowth into porous-surfaced implants. Clin Orthop Relat Res 1986:108-13.

Sasso M, Talmant M, Haiat G, Naili S, Laugier P. Analysis of the Most Energetic Late Arrival in Axially Transmitted Signals in Cortical Bone. IEEE Trans Ultrason Ferroelectr Freq Control. 2009; 56:2463-70.

Schandelmaier S, Kaushal A, Lytvyn L, Heels-Ansdell D, Siemieniuk RAC, Agoritsas T, Guyatt GH, Vandvik PO, Couban R, Mollon B, Busse JW. Low intensity pulsed ultrasound for bone healing: systematic review of randomized controlled trials. BMJ 2017; 356:1-16.

Schulte W, d'Hoedt B, Lukas D, Muhlbradt L, Scholz F, Bretschi J, Frey D, Gudat H, Konig M, Markl M, et al. [Periotest--a new measurement process for periodontal function]. Zahnarztliche Mitteilungen 1983; 73:1229-30, 33-6, 39-40.

Shalabi M, Wolke J, Cuijpers V, A Jansen J. Evaluation of bone response to titanium-coated polymethyl methacrylate resin (PMMA) implants by X-ray tomography. J Mater Sci Mater Med 2007; 18:2033-9.

Szmukler-Moncler S, Salama H, Reingewirtz Y, Dubruille JH. Timing of loading and effect of micromotion on bone-dental implant interface: review of experimental literature. J Biomed Mater Res 1998; 43:192-203.

Tanzer M, Harvey E, Kay A, Morton P, Bobyn J. Effect of noninvasive low-intensity ultrasound on bone growth into porous-coated implants. J Orthop Res 1996; 14:901-06.

Tanzer M, Kantor S, Bobyn J. Enhancement of bone growth into porous intramedullary implants using non-invasive low intensity ultrasound. J Orthop Res 2001; 19:195-99.

Ustun Y, Erdogan O, Kurkcu M, Akova T, Damlar İ. Effects of Low-Intensity Pulsed Ultrasound on Dental Implant Osseointegration: A Preliminary Report. European Journal of Dentistry 2008; 2:254-

$30 \quad 62$.

Van Scotter DE, Wilson CJ. The Periotest method for determining implant success. J Oral Implantol 1991; 17:410-3.

Vayron R, Barthel E, Mathieu V, Soffer E, Anagnostou F, Haiat G. Nanoindentation Measurements of Biomechanical Properties in Mature and Newly Formed Bone Tissue Surrounding an Implant. Journal of Biomechanical Engineering 2012; 134:021007.

Vayron R, Karasinski P, Mathieu V, Michel A, Loriot D, Richard G, Lambert G, Haiat G. Variation of the ultrasonic response of a dental implant embedded in tricalcium silicate-based cement under cyclic loading. Journal of Biomechanics 2013; 46:1162-68.

Vayron R, Mathieu V, Michel A, Haïat G. Assessment of In Vitro Dental Implant Primary Stability Using an Ultrasonic Method. Ultrasound in Medicine \& Biology 2014; 40:2885-94.

Vayron R, Matsukawa M, Tsubota R, Mathieu V, Barthel E, Haiat G. Evolution of bone biomechanical properties at the micrometer scale around titanium implant as a function of healing time. Physics in medicine and biology 2014; 59:1389-406.

Vayron R, Nguyen V-H, Bosc R, Naili S, Haïat G. Finite element simulation of ultrasonic wave propagation in a dental implant for biomechanical stability assessment. Biomech Model Mechanobiol 2015; 14:1021-32.

Vayron R, Nguyen V-H, Bosc R, Naili S, Haïat G. Assessment of the biomechanical stability of a dental implant with quantitative ultrasound: A three-dimensional finite element study. The Journal of the Acoustical Society of America 2016; 139:773-80.

50 Vayron R, Nguyen V-H, Lecuelle B, Albini Lomami H, Meningaud J-P, Bosc R, Haiat G. Comparison of Resonance Frequency Analysis and of Quantitative Ultrasound to Assess Dental Implant Osseointegration. Sensors (Basel, Switzerland) 2018; 18:1397. 
Vayron R, Nguyen VH, Lecuelle B, Haiat G. Evaluation of dental implant stability in bone phantoms: Comparison between a quantitative ultrasound technique and resonance frequency analysis. Clinical implant dentistry and related research 2018; 20:470-78.

Vayron R, Soffer E, Anagnostou F, Haïat G. Ultrasonic evaluation of dental implant osseointegration. Journal of Biomechanics 2014; 47:3562-68. 


\section{Figure captions}

Fig. 1: (a) Schematic representation of the experimental setup with an ultrasonic transducer screwed into a dental implant. The x-axis corresponds to the implant axis. Arrows represent the positions corresponding to the results shown in Fig. 2 and 3. The dotted line represent the positions where radial displacements were numerically assessed to plot dispersion curves. (b) Ultrasonic probe and dental implant used experimentally.

Fig. 2: Variation of the displacement measured at the extremity of the implant as a function of time for three measurements performed after screwing and unscrewing the transducer to the implant.

Fig. 3: Variation of the displacement at the implant surface measured experimentally as a function of time (a) at the beginning of the threading $(x=1.5 \mathrm{~mm}),(b)$ at the middle of the threading $(x=4.35 \mathrm{~mm})$, and $(c)$ at the end of the threading $(x=8.3 \mathrm{~mm})$.

15

Fig. 4: Frequency spectra corresponding to the modulus of the Fast Fourier Transform (FFT) of the signals measured experimentally (a) at the beginning of the threading ( $x=1.5$ $\mathrm{mm}),(\mathrm{b})$ at the middle of the threading $(x=4.35 \mathrm{~mm})$ and $(\mathrm{c})$ at the end of the threading $(x=8.3 \mathrm{~mm})$.

Fig. 5: Variation of (a) the peak-to-peak amplitude of the displacement at the implant surface and (b) the time of the first arriving signal (FAS) as a function of the position along the implant axis. The solid line in b) corresponds to a linear regression analysis leading to a FAS velocity equal to $2110 \mathrm{~m} / \mathrm{s}$. 
Fig. 6: (a) Variation of the displacement measured experimentally (black lines) and simulated numerically (grey lines) for $f_{c}=10 \mathrm{MHz}$ as a function of time at the extremity of the implant. (b) Frequency spectrum associated to each signal.

5 Fig. 7: Fast Fourier Transforms (FFT) of the displacement simulated at the extremity of the implants for transducer of central frequencies equal to $1 \mathrm{MHz}, 5 \mathrm{MHz}$ and $10 \mathrm{MHz}$.

Fig. 8: Intensity distribution ( $d B$ scale) of the modes propagating in a dental implant in the wavenumber-frequency diagram. The lines correspond to the variation of the phase velocity as a function of the frequency (dispersion curves) of the first three longitudinal modes corresponding to the propagation in a hollow cylinder with an external (respectively internal) diameter of $3.6 \mathrm{~mm}$ (respectively $1.6 \mathrm{~mm}$ ) obtained with the software Disperse (Pavlakovic, et al. 1997). 
a.

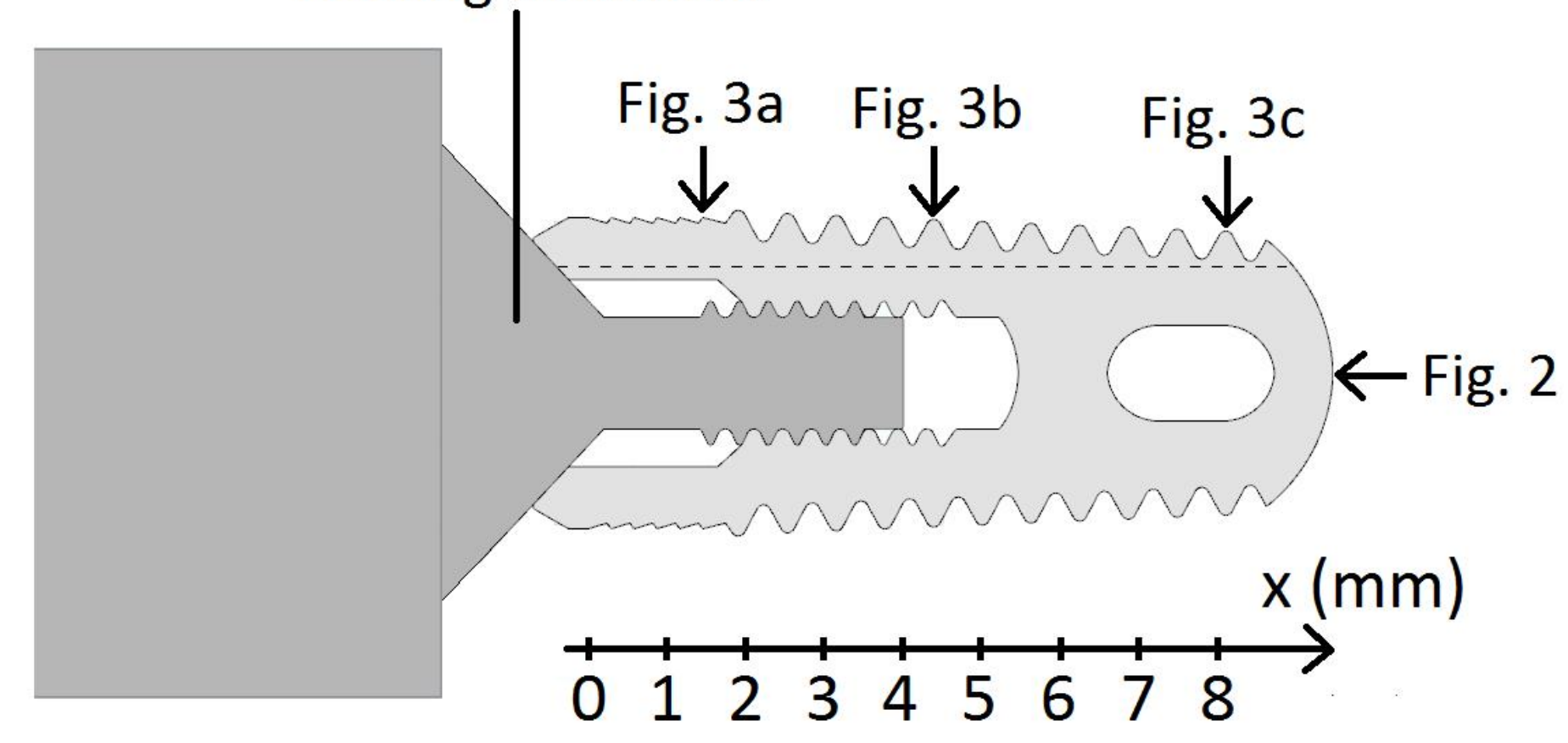

b.

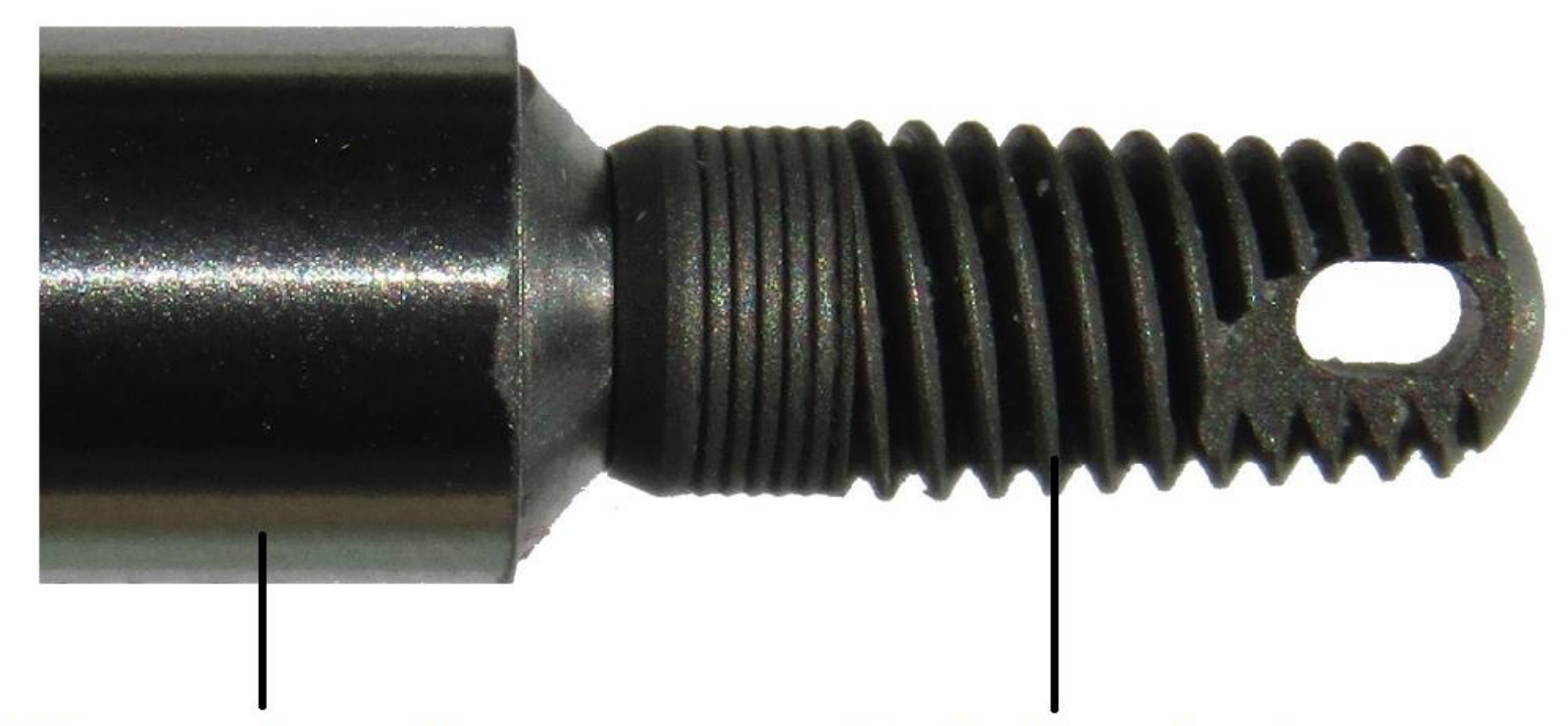




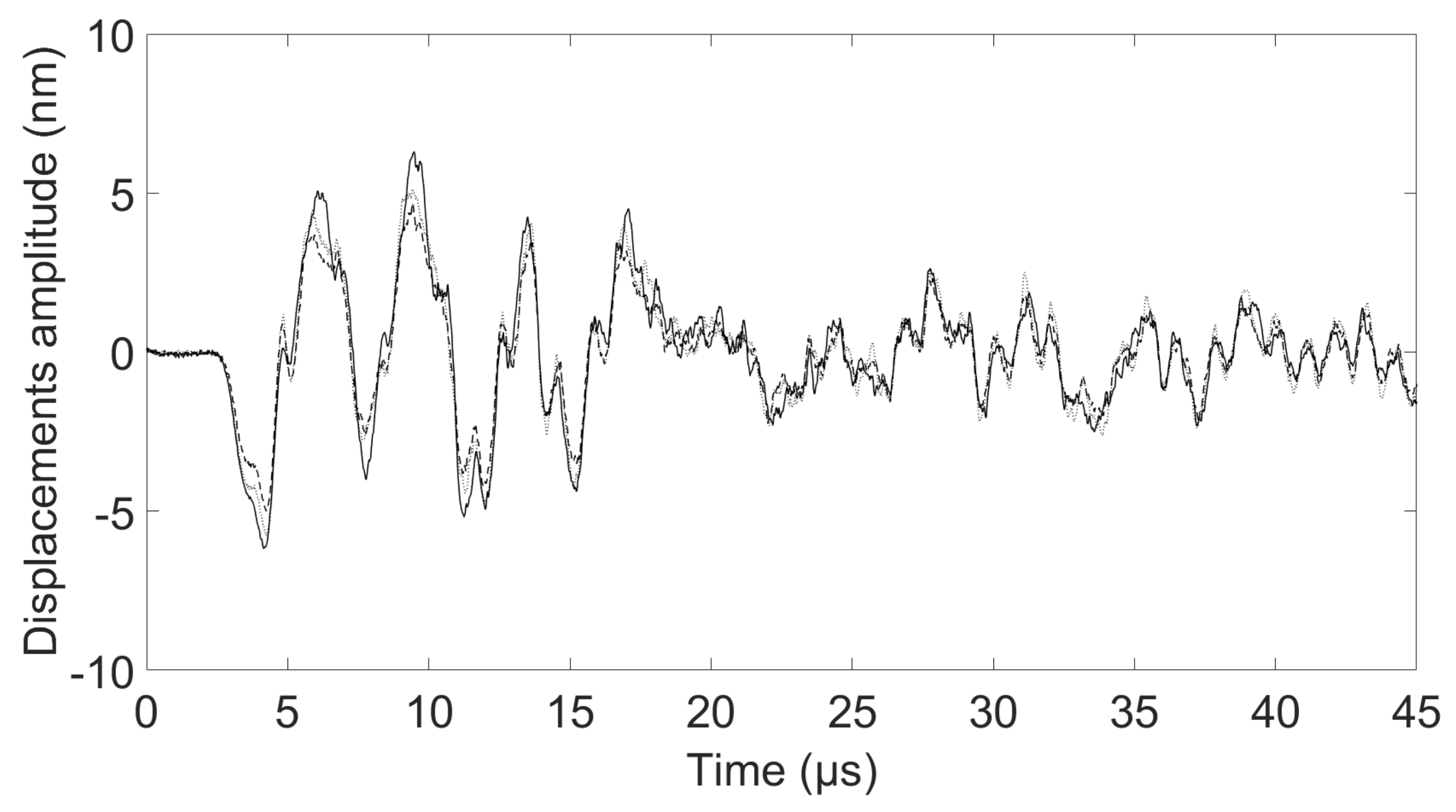


a.

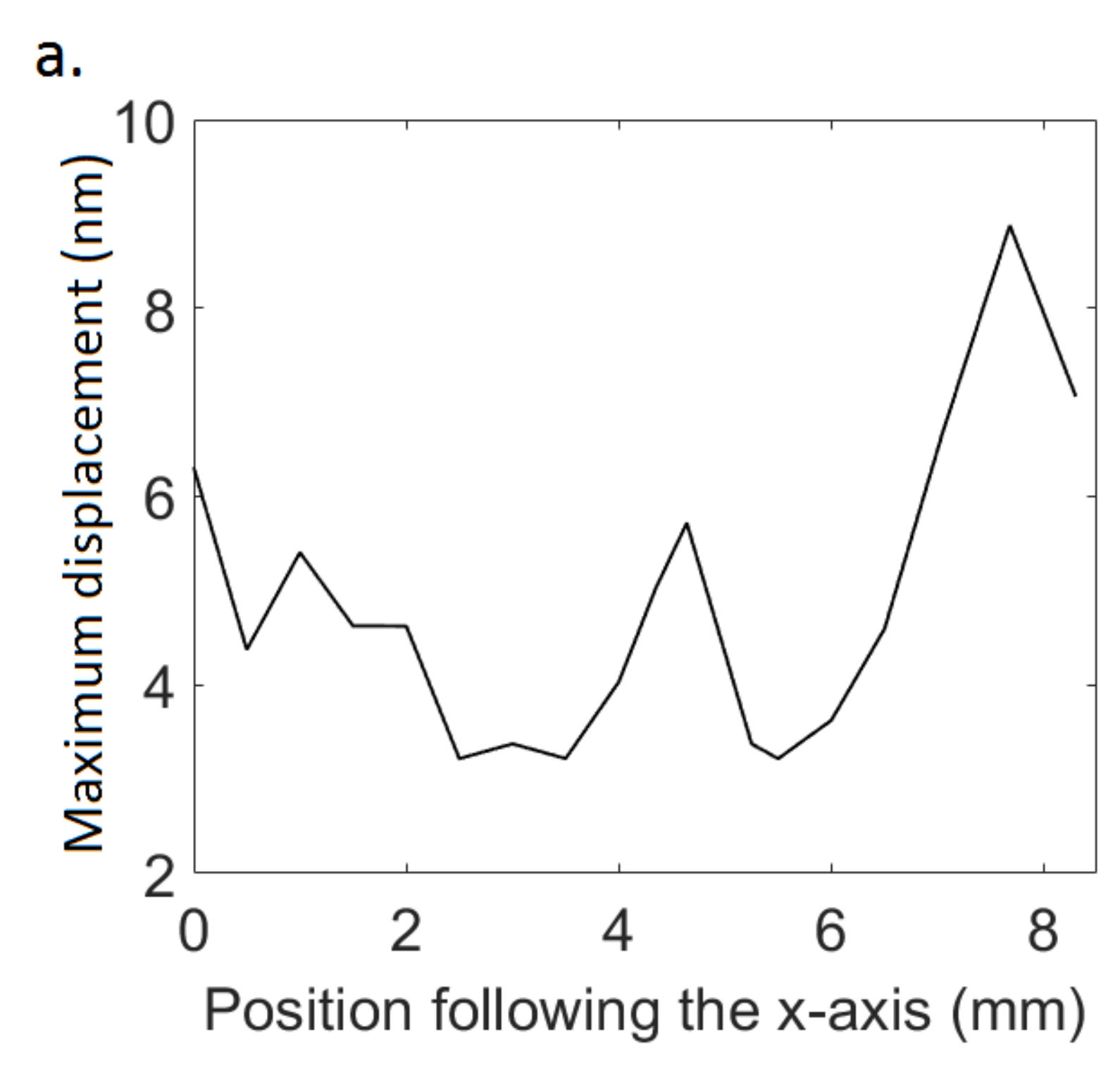

b.

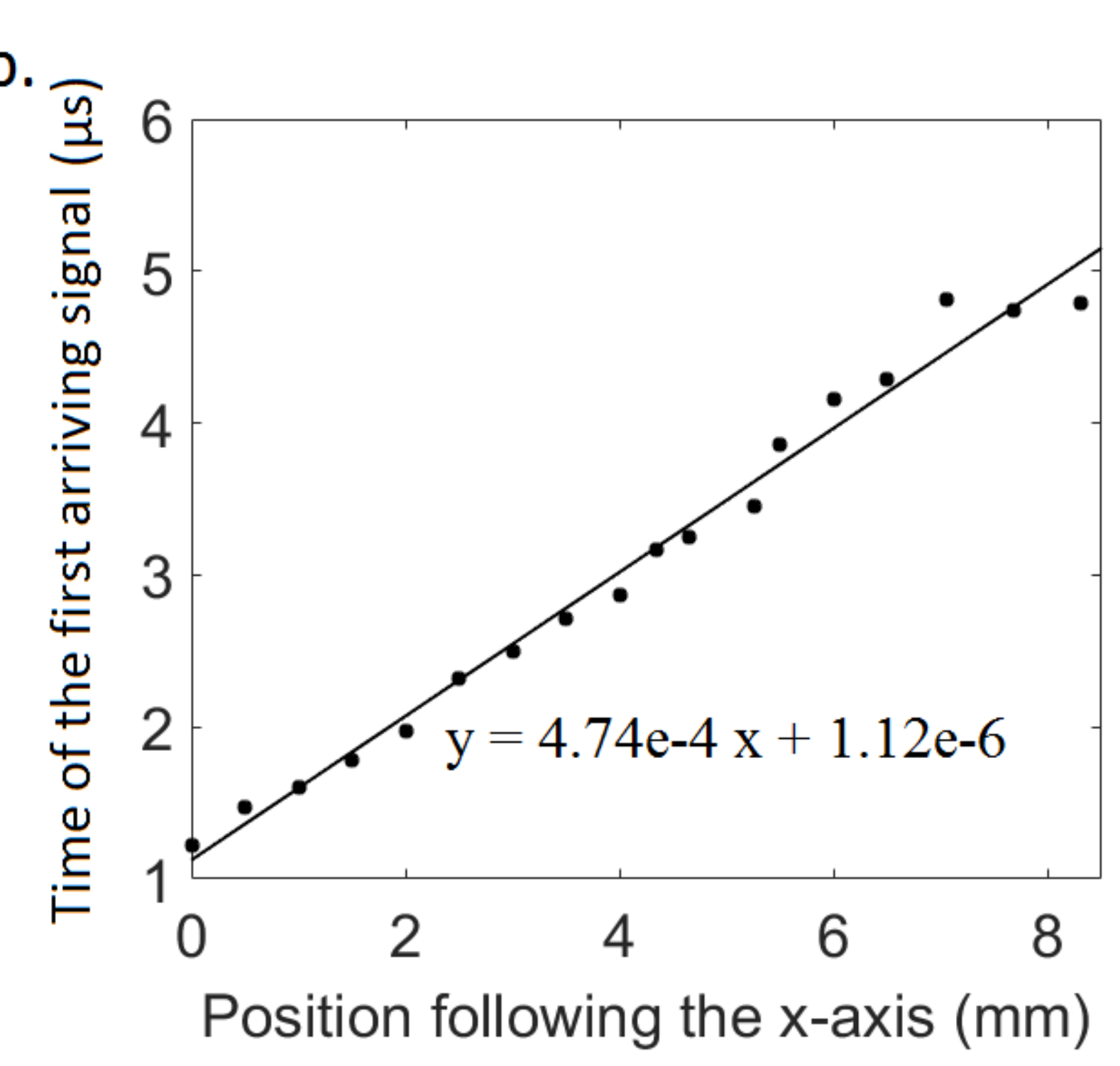




\section{a. Signals}

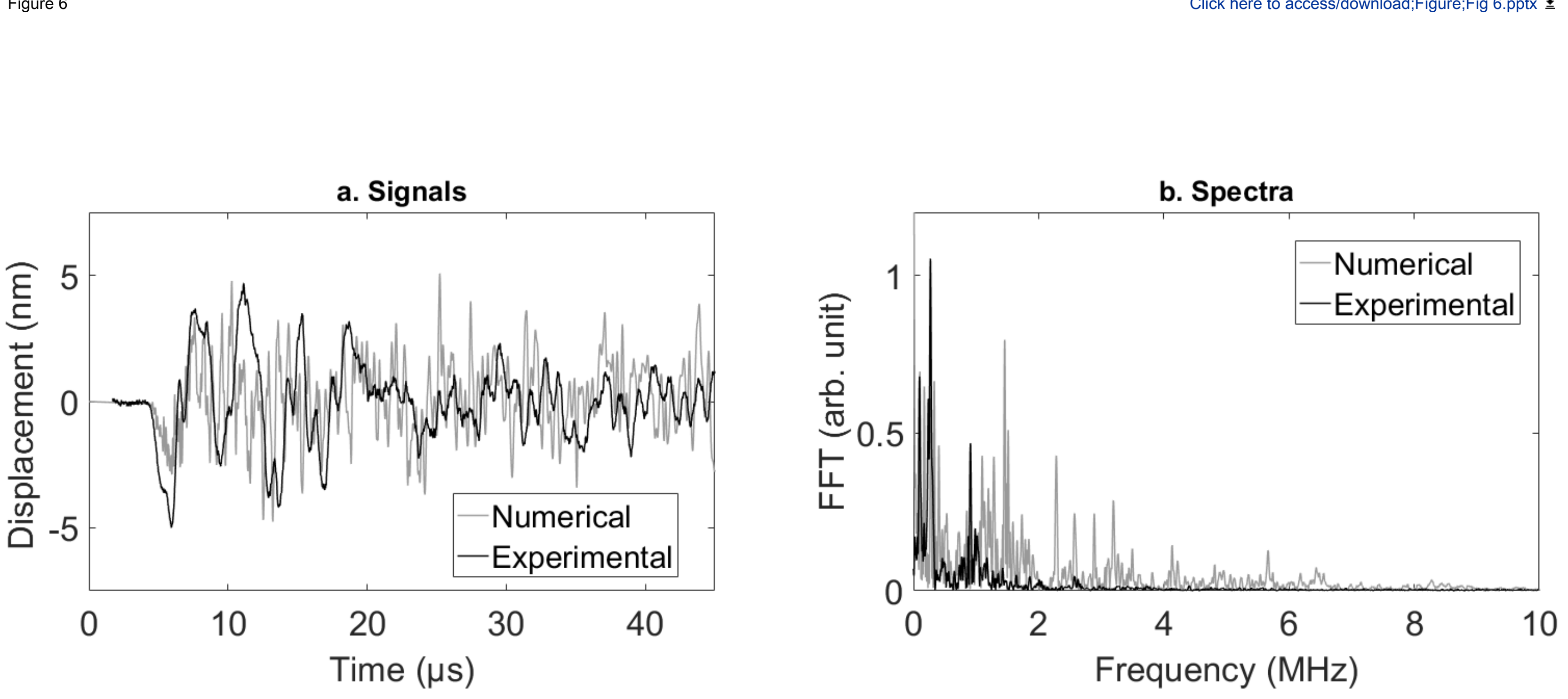

b. Spectra

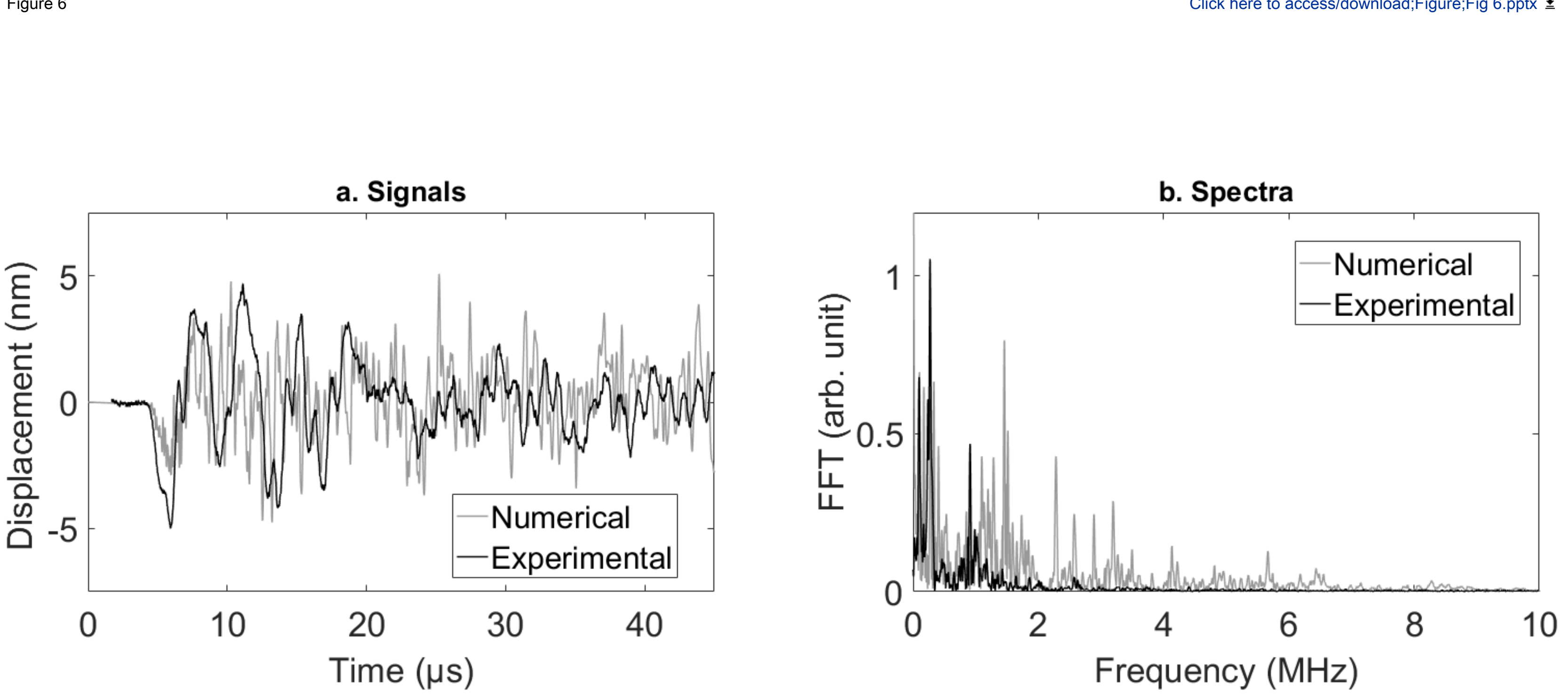




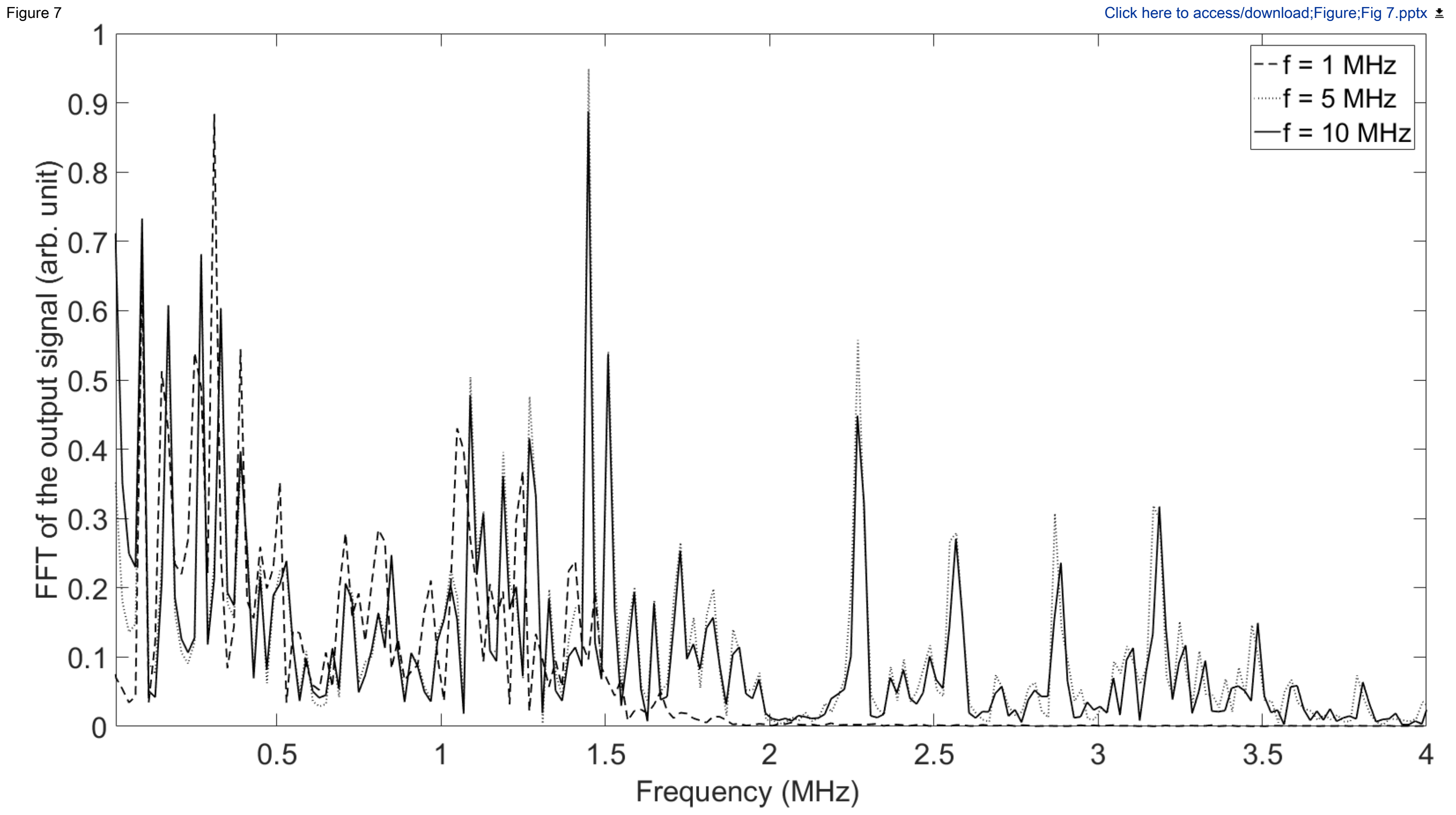


